\title{
Optimization and evaluation of CBSOL LE red wool dye adsorption from aqueous solution onto commercial activated carbon
}

\author{
P. Kaur - A. P. Singh - A. K. Prince • \\ J. P. Kushwaha
}

Received: 9 May 2014/Revised: 29 October 2014/ Accepted: 9 December 2014/Published online: 18 December 2014

(C) Islamic Azad University (IAU) 2014

\begin{abstract}
Adsorptive removal of CBSOL LE red wool dye form aqueous solution onto commercial activated carbon (CAC) was investigated in a batch system. Various process parameters like $\mathrm{pH}$, dosage of $\mathrm{CAC}(m)$ and adsorption time $(t)$ were considered and optimized with full factorial central composite design under response surface methodology. At optimized parameters, kinetic and thermodynamic studies were performed and adsorption equilibrium data were represented using Freundlich, Langmuir and Redlich-Peterson (R-P) isotherm models. Also, diffusivity was calculated for the rate-limiting step in the adsorption process. Optimum process parameters were found to be $m=2.92 \mathrm{~g} / 100 \mathrm{ml}, \quad t=6.75 \mathrm{~h}$ and $\mathrm{pH}=3.95$, and at these optimized parameters, $\%$ removal of CBSOL LE red wool dye $(Y)$ was found to be $86 \%$. Pseudo-second-order kinetic was found to best fit the adsorption kinetic data. Freundlich and R-P isotherms were found to best represent the equilibrium adsorption data. Diffusivity for the intra-particle diffusion was found to be $9.676 \times 10^{-8}$ and $1.396 \times 10^{-8} \mathrm{~m}^{2} / \mathrm{s}$ at initial concentration of CBSOL LE red wool dye $\left(C_{0}\right)$ of 50 and $100 \mathrm{mg} / \mathrm{l}$, respectively.
\end{abstract}

Keywords CBSOL LE red wool dye - Commercial activated carbon - Adsorption kinetics · Isotherms . Diffusivity $\cdot$ Response surface methodology

\section{P. Kaur}

School of Energy and Environment, Thapar University, Patiala, Punjab, India

A. P. Singh · A. K. Prince · J. P. Kushwaha $(\bowtie)$

Department of Chemical Engineering, Thapar University,

Patiala, Punjab, India

e-mail: jps_kag@yahoo.co.in

\section{Introduction}

Colored effluents produced from the textile/dyeing industries are discharged into water bodies since the dyeing technique was invented (Chiou and Chuang 2006). More than 100,000 commercially available dyes with over $7 \times 10^{5}$ tonnes of dyestuff are produced and used annually (Ramaraju et al. 2013). Most of these dyes belong to synthetic dyes that present increased environmental hazard due to being toxic in nature (Lemlikchi et al. 2012).

CBSOL LE dyes are reactive dyes developed for wool dyeing (http://www.colorbandindia.com/cbsol-le-reactivedyes-for-wool.html). Reactive dyes are azo-based chromophores combined with different types of reactive groups and are most commonly used type of dyes. Also, reactive dyes are non-biodegradable and can be carcinogenic to human (Gregory 1986). During the textile processing, large amount of dyes stay behind in wastewater produced, due to which textile wastewater becomes strong in color and toxic (Yazdani et al. 2012). Hence, the removal of dyes from wastewater is very important from both points of view of environment as well as human health.

Due to non-biodegradability of reactive dyes, physicochemical methods such as chemical coagulation, adsorption and membrane filtration are generally used for the treatment of dye-containing wastewater (Georgiou et al. 2002; Izares et al. 2006). Drawback of chemical coagulation is that it produces secondary pollutants, and membrane processes are very expensive, whereas adsorption process presents simple design, low-cost, easy operation and insensitivity to toxic substances (Chakraborty et al. 2012; Chowdhury and Saha 2010).

Various authors have reported reactive dye adsorption from wastewater on verities of low-cost adsorbents like tannery sludge developed activated carbon (Geethakarthi 
and Phanikumar 2011); sugarcane bagasse ash (Gaikwad et al. 2010); groundnut shell prepared activated carbon (Malik et al. 2006); mangrove bark (Seey et al. 2012); corn cob and sunflower seed shells (Suteu et al. 2011a, b); pineapple leaf powder (Weng et al. 2009); and agricultural waste-based activated carbon (Manoochehri et al. 2010; Parvathi and Maruthavanan 2010). A good review on methylene blue adsorption by low-cost adsorbent is available in the literature (Rafatullaha et al. 2010). Among various low-cost adsorbent, commercial activated carbon (CAC) has been reported having highest adsorption capacity (Rafatullaha et al. 2010; Singh and Kushwaha 2014). Among the studies available in the literature, none of the works reports about removal of CBSOL LE red wool dye.

In present work, adsorption of CBSOL LE red wool dye on the CAC was investigated. Various adsorption process parameters like $\mathrm{pH}$, dosage of CAC $(m)$ and adsorption time $(t)$ were considered and optimized with the help of full factorial central composite design (CCD) under response surface methodology (RSM). At optimized operational parameters, kinetics and thermodynamics of adsorption process have been studied, and change in Gibbs energy $\left(\Delta G_{0}\right)$, entropy $\left(\Delta S_{0}\right)$ and enthalpy $\left(\Delta H_{0}\right)$ was determined at various temperatures. To represent the adsorption equilibrium data at optimized parameters, Freundlich, Langmuir and Redlich-Peterson (R-P) isotherm models were used. Also, diffusivity was calculated for the rate-limiting step in the adsorption process.

\section{Materials and methods}

Adsorbent and adsorbate

CAC was purchased from Pneumatic Engineers Spares and Service, New Delhi, India, and it was used as procured. Detailed physicochemical characteristics of the CAC have already been presented elsewhere (Singh and Kushwaha 2014). The BET surface area and BET average pore diameter of CAC were found to be $222.33 \mathrm{~m}^{2} / \mathrm{g}$ and $26.56 \AA$, respectively. The average particle diameter and bulk density of CAC were found to be $1.58 \mathrm{~mm}$ and $540.22 \mathrm{~kg} / \mathrm{m}^{3}$, respectively.

CBSOL red LE wool dye (supplied by Grasim industry, Nagda, Madhya Pradesh, India) was dissolved in distilled water to make the dye solution. For this, $1 \mathrm{~g} / \mathrm{l}$ of stock dye solution was prepared, which was further diluted to make the working solution of desired concentration as per the experimental requirement.
Experimental design, procedure and data analysis

In this study, experiments for the adsorption of CBSOL LE red wool dye from aqueous solution on $\mathrm{CAC}$ were designed and conducted in accordance with CCD of Design-Expert ${ }^{\circledR}$ 6.0 under RSM. The RSM is a statistical tool which helps to design the experiments and optimize the effective parameters for desirable responses providing process models. With RSM, analysis of the interaction between parameters on responses is possible with reduced number of experiments (Soo et al. 2004). Three adsorption process parameters (pH: 3-9; $m$ : 0.5-5 g/100 $\mathrm{ml}$ and $t: 1-7 \mathrm{~h}$ ) with five levels were used to design experiments using RSM, and percentage CBSOL red LE wool dye removal $(Y)$ has been taken as a response of the system. Experimental design matrix is given in Table 1.

A total of 20 experiments were conducted as suggested by RSM. The experiments were conducted in batch mode to study the effects of the three process parameters on response $Y$. For each set of suggested adsorption experiments, $100 \mathrm{ml}$ solution of previously adjusted $\mathrm{pH}$ of CBSOL red LE wool dye having $100 \mathrm{mg} / \mathrm{l}$ concentration $\left(C_{0}\right)$ was taken in 250-ml stoppered conical flasks. Thereafter, CAC was added to the flask as per design matrix. Initial $\mathrm{pH}$ of the solutions was adjusted by using $0.1 \mathrm{~N} \mathrm{H}_{2} \mathrm{SO}_{4}$ and $0.1 \mathrm{~N}$ $\mathrm{NaOH}$ solutions. The flasks were then kept into temperature-controlled orbital shaking incubator (Remi Elektronik Ltd., India; CIS-24 Plus), and the mixture was agitated at constant speed of $150 \mathrm{rpm}$ at temperature $(T) 303 \mathrm{~K}$ for desired time (as per design matrix) to attain equilibrium.

The adsorbent and adsorbate were separated from the mixture after desired time (as per design matrix) by filtering the mixture with Whatman no.1 filter paper, and filtrate was analyzed for residual CBSOL LE red wool dye concentration $\left(C_{\mathrm{e}}\right)$, using a double beam UV-visible spectrophotometer (Electronic Corporation India Ltd., UV 5704SS) at $\lambda_{\max }=504 \mathrm{~nm}$. The $\%$ color removal $(Y)$ was then calculated using the following relation:

$Y=\frac{\left(C_{0}-C_{\mathrm{e}}\right) 100}{C_{0}}$

Similarly, for the equilibrium adsorption uptake, $q_{\mathrm{e}}(\mathrm{mg} / \mathrm{g})$ was calculated as:

$q_{\mathrm{e}}=\frac{\left(C_{0}-C_{\mathrm{e}}\right)}{m} V$

where $C_{\mathrm{e}}$ is the equilibrium adsorbate concentration, $V$ is the volume of the adsorbate (1), and $m$ is the mass of adsorbent (g). 
Table 1 Full factorial design used and responses for the \% removal CBSOL red LE wool dye by CAC

\begin{tabular}{llllr}
\hline $\mathrm{pH}$ & $T(\mathrm{~h})$ & $m(\mathrm{~g} / 100 \mathrm{ml})$ & \multicolumn{2}{c}{ \% Dye removal $(Y)$} \\
\cline { 3 - 5 } & & & Actual & Predicted \\
\hline 4.5 & 2.5 & 1.625 & 26.94 & 42.13 \\
7.5 & 2.5 & 1.625 & 35.36 & 36.17 \\
4.5 & 5.5 & 1.625 & 63.07 & 62.10 \\
7.5 & 5.5 & 1.625 & 43.33 & 50.52 \\
4.5 & 2.5 & 3.875 & 93.71 & 101.22 \\
7.5 & 2.5 & 3.875 & 45.35 & 61.02 \\
4.5 & 5.5 & 3.875 & 91.78 & 105.67 \\
7.5 & 5.5 & 3.875 & 60.34 & 59.85 \\
3 & 4 & 2.75 & 88.23 & 77.76 \\
9 & 4 & 2.75 & 30.23 & 25.99 \\
6 & 1 & 2.75 & 76.94 & 64.70 \\
6 & 7 & 2.75 & 85.97 & 83.50 \\
6 & 4 & 0.5 & 22.30 & 18.54 \\
6 & 4 & 5 & 97.90 & 86.96 \\
6 & 4 & 2.75 & 85.00 & 80.61 \\
6 & 4 & 2.75 & 84.36 & 80.61 \\
6 & 4 & 2.75 & 82.74 & 80.61 \\
6 & 4 & 2.75 & 81.13 & 80.61 \\
6 & 4 & 2.75 & 81.78 & 80.61 \\
6 & 4 & 2.75 & 83.39 & 80.61 \\
\hline
\end{tabular}

The response of the system, $Y$, obtained was processed for Eq. (3) with Design-Expert ${ }^{\circledR}$ 6.0. through ANOVA to obtain the interaction between the process variables and the response.

$Y=c_{o}+\sum_{i=1}^{4} c_{i} X_{i}+\sum_{i=1}^{4} c_{i i} X_{i}^{2}+\sum_{i=j}^{3} \sum_{i=j+1}^{4} c_{i j} X_{i j}$

where $Y$ is response, $c_{o}, c_{i}, c_{i i}, c_{i j}$ are constant coefficients, and $X_{i}$ the independent process variables.

The fit quality of second-order polynomial model was expressed by the coefficient of determination $R^{2}$ and adjusted $R^{2}$. For optimization, desirability function module of Design Expert 6.0 was utilized, in which individual goals are combined into an overall desirability function for maximization to find the best maximum of response $(\mathrm{Gu}-$ ven et al. 2008).

\section{Results and discussions}

\section{Model equation and validation}

The response of the system, $Y$, (Table 1) obtained was processed with Design-Expert ${ }^{\circledR}$ 6.0. Sequential model sum of squares, model summary statistics and ANOVA were
Table 2 ANOVA for response surface quadratic model

\begin{tabular}{|c|c|c|c|c|c|}
\hline Source & $\begin{array}{l}\text { Sum of } \\
\text { squares }\end{array}$ & $d f$ & $\begin{array}{l}\text { Mean } \\
\text { square }\end{array}$ & $F$ value & Prob $>F$ \\
\hline Model & $10,533.12$ & 9 & $1,170.35$ & 9.41 & 0.0008 \\
\hline A & $2,680.75$ & 1 & $2,680.75$ & 21.55 & 0.0009 \\
\hline B & 353.59 & 1 & 353.59 & 2.84 & 0.1227 \\
\hline $\mathrm{C}$ & $4,681.84$ & 1 & $4,681.84$ & 37.64 & 0.0001 \\
\hline $\mathrm{A}^{2}$ & $1,297.88$ & 1 & $1,297.88$ & 10.44 & 0.0090 \\
\hline $\mathrm{B}^{2}$ & 66.67 & 1 & 66.66 & 0.54 & 0.4809 \\
\hline$C^{2}$ & $1,220.14$ & 1 & $1,220.14$ & 9.81 & 0.0107 \\
\hline $\mathrm{AB}$ & 15.77 & 1 & 15.77 & 0.13 & 0.7292 \\
\hline $\mathrm{AC}$ & 586.19 & 1 & 586.19 & 4.71 & 0.0551 \\
\hline $\mathrm{BC}$ & 120.49 & 1 & 120.49 & 0.97 & 0.3482 \\
\hline Residual & 1243.70 & 10 & 124.37 & & \\
\hline $\begin{array}{l}\text { Lack of } \\
\text { fit }\end{array}$ & $1,232.68$ & 5 & 246.54 & 111.80 & $<0.0001$ \\
\hline Pure error & 11.025 & 5 & 2.20 & & \\
\hline Cor total & $11,776.82$ & 19 & & & \\
\hline \multicolumn{6}{|l|}{$\mathrm{A}: \mathrm{pH}$} \\
\hline \multicolumn{6}{|l|}{$\mathrm{B}: t$} \\
\hline $\mathrm{C}: m$ & & & & & \\
\hline
\end{tabular}

analyzed, and it was suggested by sequential model sum of squares that quadratic model most suitably described the dye removal from aqueous solution. Suggested quadratic equation is given below:

$$
\begin{aligned}
Y= & 80.61-12.94 \mathrm{pH}+4.7 t+17.11 m-7.18 \mathrm{pH}^{2} \\
& -1.63 t^{2}-6.97 m^{2}-1.4(\mathrm{pH} \times t)-8.56(\mathrm{pH} \times m) \\
& -3.88(t \times m)
\end{aligned}
$$

ANOVA result is shown in Table 2. Model $F$ value of 9.41 and model Prob $>F$ value of 0.0008 for $\%$ dye removal imply that quadratic model fitted is significant. Value of "Prob $>F$ " $<0.05$ indicates model terms are significant. ANOVA from the response surface models shows that $\mathrm{pH}, m, \mathrm{pH}^{2}$ and $m^{2}$ are significant terms for response $Y$, implying that quadratic model (Eq. 4) can be used to predict response $Y$ for CBSOL red LE wool dye from the aqueous solution.

Normal \% probability plot of residuals and plot of studentized residuals versus predicted were evaluated (not shown here). The normality assumption was relatively satisfied as the points in the plot form fairly straight line for response $Y$. For a reliable model, no series of increasing or decreasing points, patterns and a predominance of positive or negative residuals should be found (Behbahani et al. 2011; Bansal et al. 2013). Generally, plot of studentized residuals versus predicted should be a random scatter, which suggests that the variance of original observations is constant for all values of the response, $Y$ (Özer et al. 2009). 
$R^{2}$ and adjusted $R^{2}$ for a regression model are evaluated to show the model fitting to experimental data. Actual versus predicted $Y$ (\% CBSOL red LE dye removal) plot (not shown here) (actual values were calculated experimentally, while predicted $Y$ values were evaluated using Design Expert 6) revealed the values of $R^{2}$ and adjusted $R^{2}$ to be 0.894 and 0.80 , which concludes a very good correlation between the experimental and the predicted values of response $Y$.

The outlier $t$ plot (not shown here) is used to measure how many standard deviations the actual value deviates from the predicted value. For a good correlation, outlier $t$ values should fall within \pm 3.50 (Özer et al. 2009; Montgomery 1996; Myers and Montgomery 2002). In present study, the outlier $t$ values were found within the interval of \pm 3.50 , concluding that the approximation of the fitted model to the response surface was fairly good.

Effect of solution $\mathrm{pH}$, adsorption time $(t)$ and dosage $(m)$

Values of response $Y$ for the adsorptive removal of CBSOL red LE wool dye with various $t(\mathrm{~h}), \mathrm{pH}$ and $m$ (g) values are presented in Table 1, and the corresponding response surface 3D plot is shown in Fig. 1.

It can be observed from Fig. 1a that $Y$ value increases with decreases in $\mathrm{pH}$, and maximum $Y$ value is found at $\mathrm{pH} \approx 5$. For all $\mathrm{pH}>5, Y$ value changes marginally. This trend of variation in $Y$ with $\mathrm{pH}$ was observed at all $t$ values. It can also be observed from Fig. 1a that when $\mathrm{pH}$ of reactive CBSOL red LE wool dye aqueous solution is less than $\approx 5$, adsorption of reactive CBSOL red LE wool dye increases with increase in $t(t \leq 5 \mathrm{~h})$, and for all $t>5 \mathrm{~h}$ values, $Y$ becomes constant. But, for $\mathrm{pH}>5$, increase in $\mathrm{pH}$ showed very minute dye adsorption at all $t$ values.

To understand the mechanism of adsorption, study for isoelectric point (point of zero charge, $\mathrm{pH}_{\mathrm{PZC}}$ ) determination of adsorbent was conducted and $\mathrm{pH}_{\mathrm{PZC}}$ was found to be 8.6. At $\mathrm{pH}$ below $\mathrm{pH}_{\mathrm{PZC}}=8.6$, due to protonation, surface of adsorbent becomes positively charged (Lakshmi et al. 2009), which favors dye adsorption, and hence, $Y$ value increases with decrease in $\mathrm{pH}$, whereas at $\mathrm{pH}>\mathrm{pH}_{\mathrm{PZC}}$, adsorbent surface becomes negatively charged due to ionization and dye adsorption is not favoured.

Response surface 3D plot of $Y$ versus $t$ and $m$ is shown in Fig. 1b. For any $t$ value, increasing $m$ up to $m \approx 2.9 \mathrm{~g}$ resulted in rapid increase in response $Y$. Further increasing $m$ values $(m>2.9 \mathrm{~g})$, response $Y$ was found to gradually decrease, and being constant to $Y=85 \%$ at all $t<5 \mathrm{~h}$

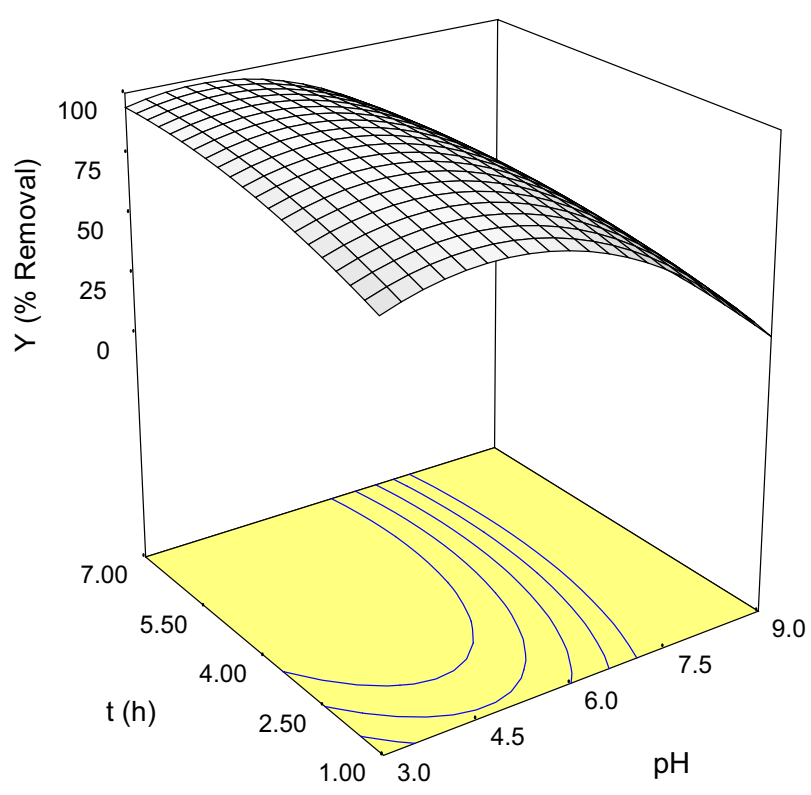

(a)

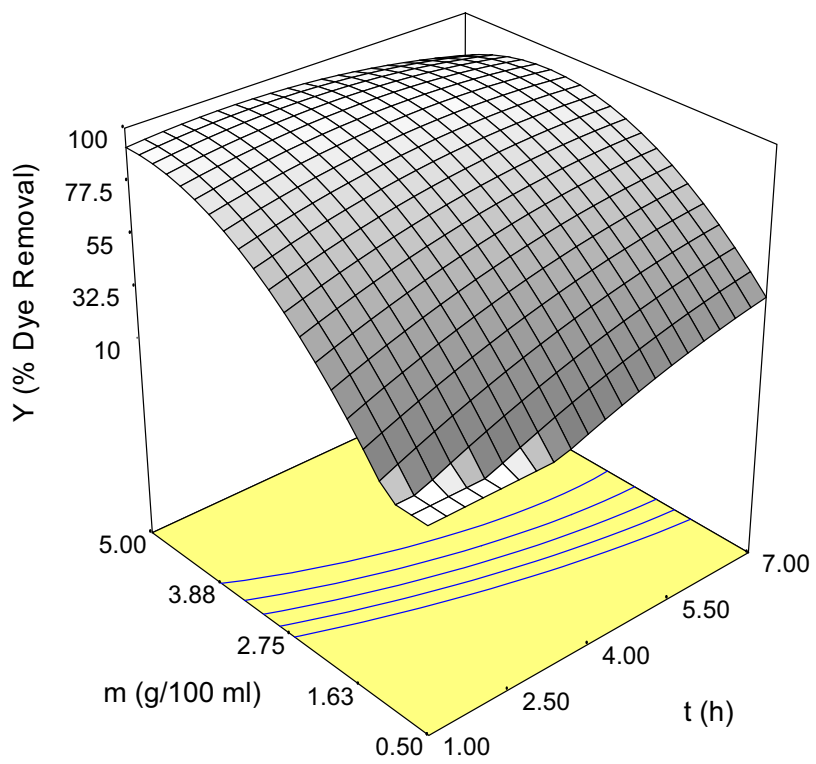

(b)

Fig. 1 Variation of CBSOL red LE wool dye \% removal $(Y)$ with $\mathbf{a} \mathrm{pH}$ and adsorption time $(t)$ and $\mathbf{b}$ adsorption time $(t)$ and adsorbent dosage $(m)$

values, while at higher $t$ values $(t>5 \mathrm{~h})$, desorption of adsorbed dye onto CAC resulted in decreased response $Y$.

Due to the increase in $m$ up to $m \approx 2.9 \mathrm{~g}$, availability of more adsorption sites increases surface for the adsorption 
Fig. 2 FTIR spectra of a bare CAC b loaded CAC with dye

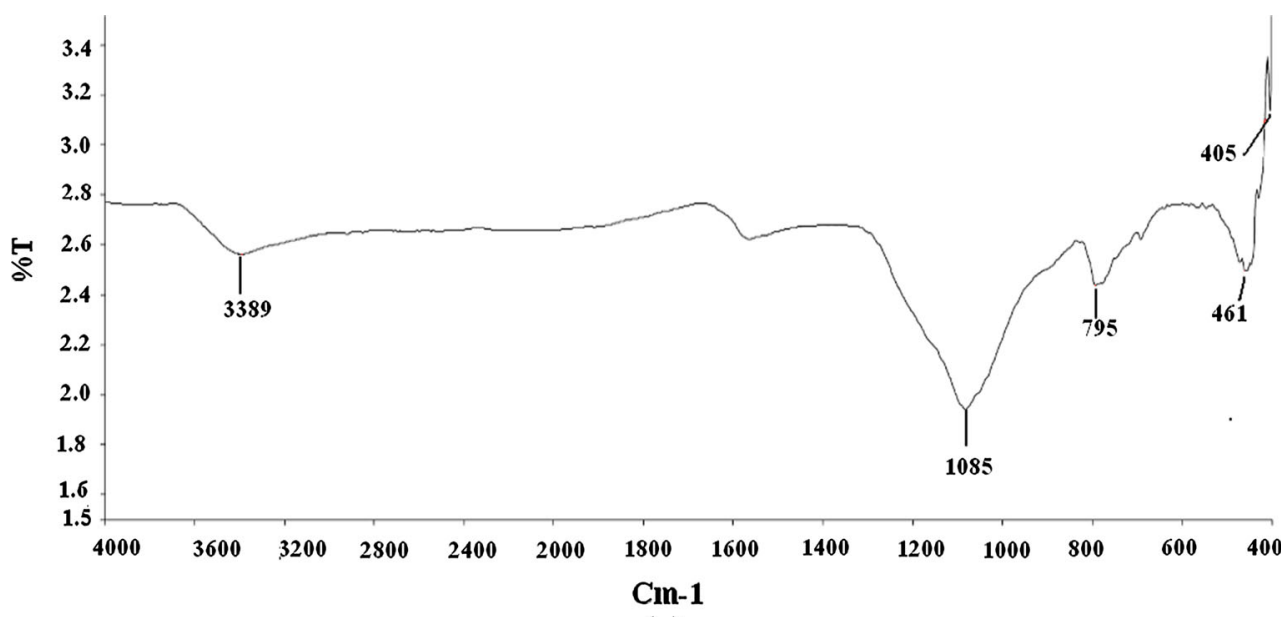

(a)

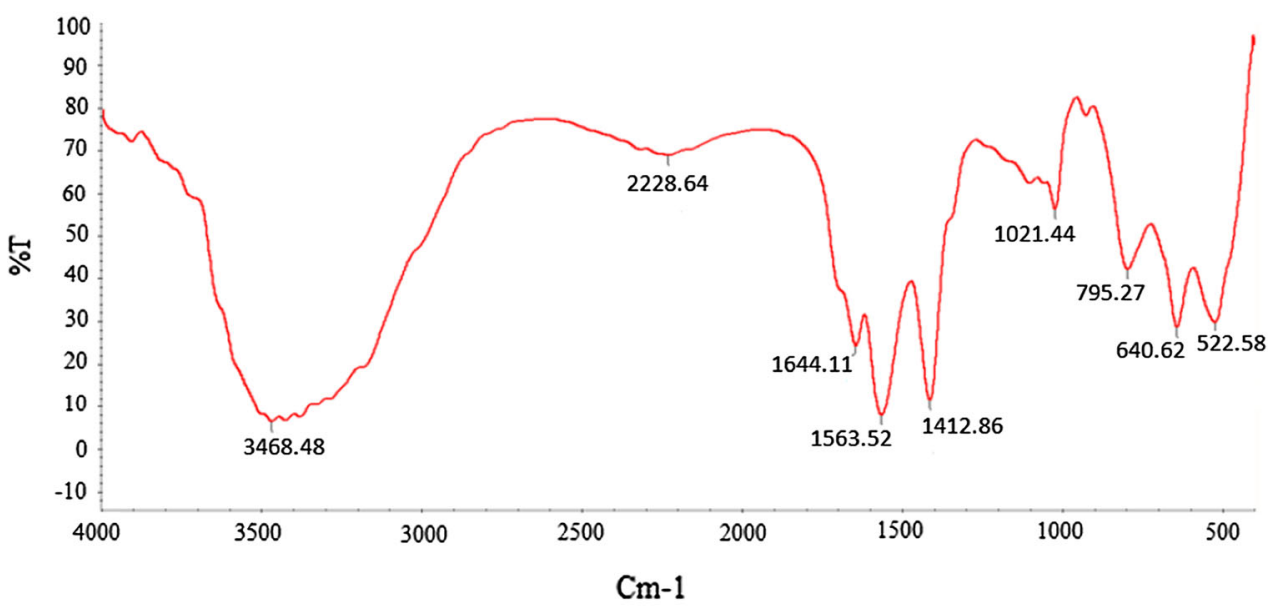

(b) of dye on CAC, and hence, sharp increase in response $Y$ is observed. Although for all $m>2.9 \mathrm{~g}$ active sites are increasing, but the adsorption is limited by the concentration of CBSOL LE red wool dye. Also, at all values of $m>2.9 \mathrm{~g}$, increase in $t$ values up to $5 \mathrm{~h}$ improves adsorption of CBSOL red LE wool but marginally, and for $t>5 \mathrm{~h}$, desorption of CBSOL red LE wool dye was observed.

Optimization and adsorbent analysis

Adsorptive treatment of CBSOL red LE wool dye was optimized for maximizing response $Y$ (\% removal). The optimized values of operational parameters under the range of study were found to be $m=2.92 \mathrm{~g} / 100 \mathrm{ml}, t=6.75 \mathrm{~h}$ and $\mathrm{pH}=3.95$. At these optimized parameters, response
$Y$ was suggested to be $86 \%$. In order to validate the result suggested by optimization, three replicate runs were conducted with the optimized parameters and the average value of response $Y$ was found to be $82.74 \%$.

However, experiments were conducted to validate the optimized process parameters and corresponding $\%$ color removal values generated for CBSOL red LE wool dye synthetic wastewater treatment with real textile industry wastewater. Real textile industry wastewater was collected from equalization tank of effluent treatment plant of a Woollen textile-based industry, located at Ludhiana, Punjab, India. For the purpose of validation, three experimental run were conducted at the optimized process parameters with the real textile wastewater. In order to calculate the \% color removal, the original and treated samples were analyzed using a double beam UV-visible spectrophotometer 
at $\lambda_{\max }=473 \mathrm{~nm}$. The average $\%$ color removal was found to be $75.42 \%$, which is in good agreement with the CBSOL red LE wool dye synthetic wastewater \% color removal.

At optimum condition, FTIR, SEM and EDX analysis of bare CAC and dye loaded CAC was conducted. The FTIR spectra of bare and dye loaded CAC are shown in Fig. 2. FTIR spectra of blank CAC were presented somewhere else. Sharp peaks at $\sim 1,085, \sim 795$ and $\sim 461 \mathrm{~cm}^{-1}$ can be seen in FTIR spectra of blank CAC (Fig. 2a). Peak at $\sim 3,389 \mathrm{~cm}^{-1}$ is due to $\mathrm{O}-\mathrm{H}$ stretching mode of hydroxyl groups (Al-qodah and Shawabkah 2009). Peak at $\sim 1,085 \mathrm{~cm}^{-1}$ may be accredited to existence of esters, carboxylic acids, alcohols and ethers, while the presence of the phenyl ring has their vibrations at $\sim 795 \mathrm{~cm}^{-1}$. Peak at $\sim 461 \mathrm{~cm}^{-1}$ may be attributed to $\mathrm{C}-\mathrm{C}$ stretching. Three peaks at $\sim 3,389, \sim 1,085$ and $\sim 795 \mathrm{~cm}^{-1}$ can be seen to be affected after dye adsorption on CAC (Fig. 2b). This indicates that the functional groups at these wave numbers participate in the dye adsorption. Also, some new additional peaks at $\sim 2,228, \sim 1,644, \sim 1,563, \sim 1,412, \sim 640$ and $\sim 522$ can be observed. Peaks at $\sim 522-640$ are due to aromatic C-H vibration (Barkauskas and Dervinyte 2004). Bands around 1,600, 1,510, 1,460 and 1,426 $\mathrm{cm}^{-1}$ are assigned to aromatic skeleton vibrations (Carrott Suhas and Carrott Ribeiro 2007). However, peak at $\sim 1,644$ and $\sim 1,563$ is due to amides and nitro group stretching, respectively.

SEM (scanning electron microscope) and EDX (energy dispersive X-ray) analysis were conducted (JEOL JSM $6390 \mathrm{LV}$ ) in order to elucidate morphology and elemental distribution, respectively, of the bare CAC and loaded CAC (Fig. 3). Bare CAC shows porous structure having pores of different sizes with uneven surface, while for loaded CAC, the surface became smoother and non-porous due to the adsorption of dye (Fig. 3). EDX analysis revealed the presence of $36.08 \%$ carbon, $38.22 \%$ oxygen, $14.88 \%$ silica and $6.83 \%$ aluminum by weight percent in bare CAC. Dye loaded CAC showed $45.55 \%$ carbon, $38.27 \%$ oxygen, $9.35 \%$ silica and $4.79 \%$ aluminum. Except these elements, magnesium, sulfur, potassium, iron and calcium were found in trace amount in both bare and loaded CAC. It can be pointed out that loaded CAC showed higher carbon in comparison with bared CAC due to adsorbed dye.

\section{Adsorption kinetics and diffusivity}

Kinetics of adsorption provides useful data for the efficiency and practicability of the adsorption for large-scale

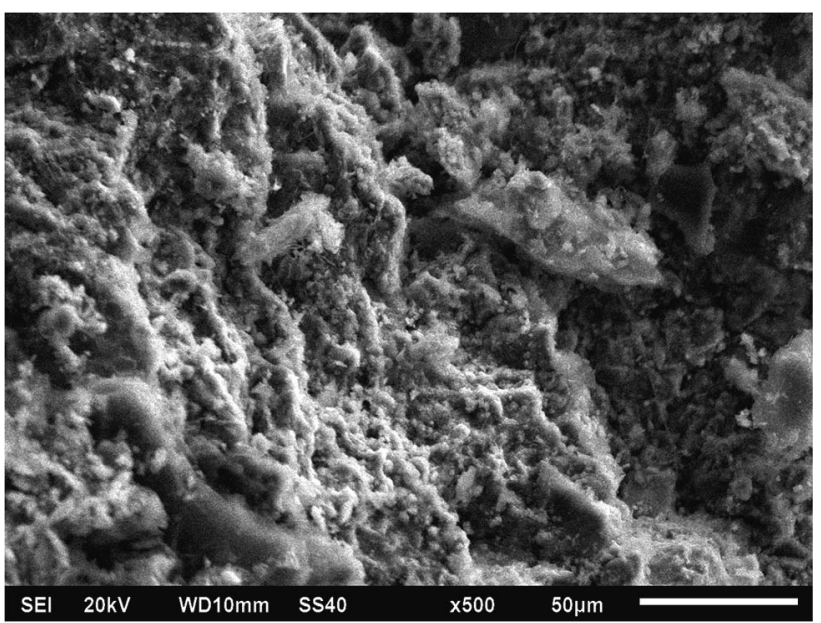

(a)

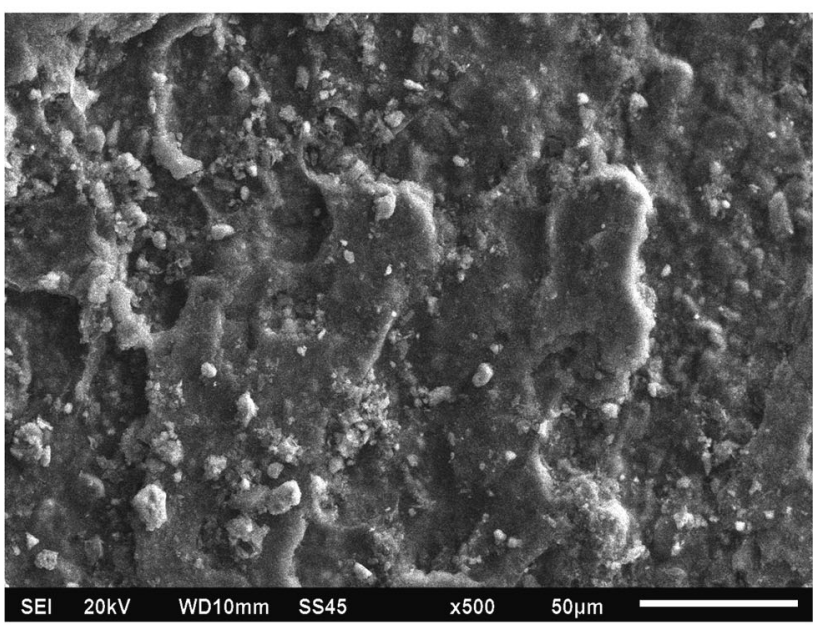

(b)

Fig. 3 SEM of a bare CAC $\mathbf{b}$ loaded CAC

operations. At optimized parameters $(m=2.92 \mathrm{~g} / 100 \mathrm{ml}$, $t=6.75 \mathrm{~h}$ and $\mathrm{pH}=3.95$ ), kinetics of adsorption of CBSOL red LE wool dye from aqueous solution on CAC was studied using Pseudo-first-order and pseudo-secondorder kinetic models. For this, solution of CBSOL red LE wool dye having initial concentration $\left(C_{0}\right) 50$ and $100 \mathrm{mg} / \mathrm{l}$ was kept in contact with the CAC at optimized parameters.

Pseudo-first-order model is given as (Malik 2003):

$q_{\mathrm{t}}=q_{\mathrm{e}}\left[1-\exp \left(-k_{\mathrm{f}} t\right)\right]$

where $q_{\mathrm{t}}$ is amount of dye adsorbed $(\mathrm{mg} / \mathrm{g}$ ) at time ( $t$ ) ( $\mathrm{min})$ and $k_{\mathrm{f}}$ is the rate constant of pseudo-first-order adsorption $\left(\min ^{-1}\right)$.

Pseudo-second-order model is represented as (Blanchard et al. 1984; Ho and McKay 1999): 
Table 3 Kinetic parameters for CBSOL red LE wool dye adsorption on CAC at optimized parameters $(m=2.92 \mathrm{~g} / 100 \mathrm{ml}, t=6.75 \mathrm{~h}$ and $\mathrm{pH}=3.95)$

\begin{tabular}{|c|c|c|c|c|c|}
\hline$C_{\mathrm{i}}(\mathrm{mg} / \mathrm{l})$ & $q_{\mathrm{e}, \exp }(\mathrm{mg} / \mathrm{g})$ & $q_{\mathrm{e}, \mathrm{cal}}(\mathrm{mg} / \mathrm{g})$ & $k_{\mathrm{f}}\left(\min ^{-1}\right)$ & $R^{2}$ (nonlinear) & MPSD \\
\hline \multicolumn{6}{|c|}{ Pseudo-first-order model } \\
\hline 100 & 2.832 & 2.565 & 0.035 & 0.97 & 31.34 \\
\hline 50 & 1.558 & 1.397 & 0.021 & 0.98 & 23.87 \\
\hline$C_{\mathrm{i}}(\mathrm{mg} / \mathrm{l})$ & $q_{\mathrm{e}, \exp }(\mathrm{mg} / \mathrm{g})$ & $k_{\mathrm{S}}(\mathrm{g} / \mathrm{mg} \min )$ & $h(\mathrm{mg} / \mathrm{g} \min )$ & $R^{2}$ (nonlinear) & MPSD \\
\hline \multicolumn{6}{|c|}{ Pseudo-second-order model } \\
\hline 100 & 2.780 & 0.018 & 0.137 & 0.99 & 17.60 \\
\hline 50 & 1.647 & 0.012 & 0.033 & 0.99 & 19.51 \\
\hline
\end{tabular}

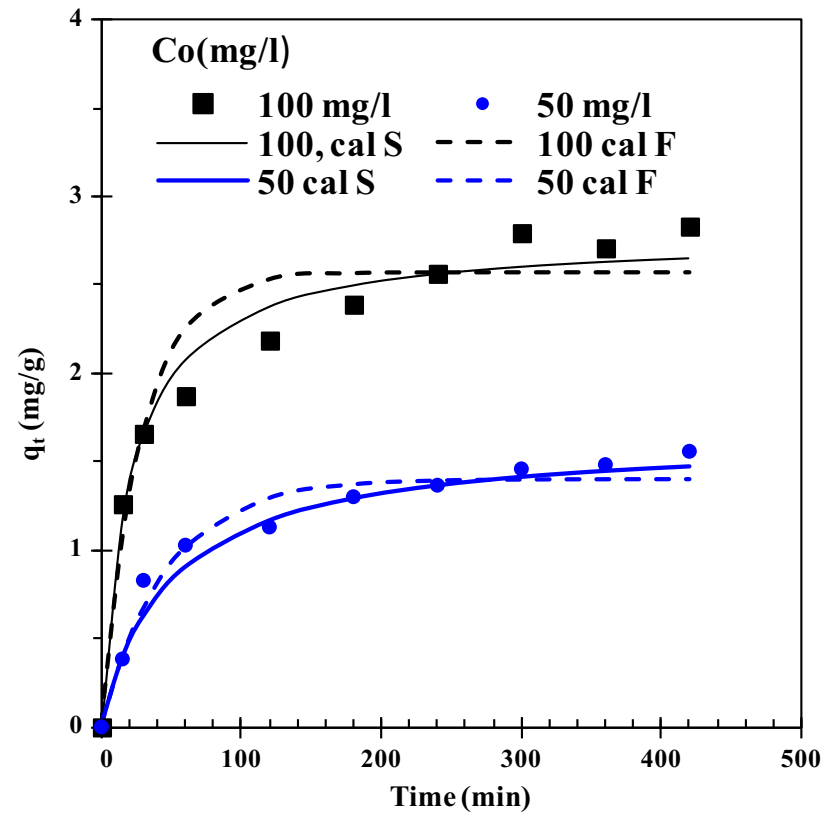

Fig. 4 Kinetics of CBSOL red LE wool dye adsorption on CAC at optimized parameters $(m=2.92 \mathrm{~g} / 100 \mathrm{ml}, \quad t=6.75 \mathrm{~h} \quad$ and $\mathrm{pH}=3.95$ ). (Experimental results are shown by data points, solid line shows pseudo-second-order kinetic model fitting, and dotted line shows pseudo-first-order kinetic model)

$q_{\mathrm{t}}=\frac{t k_{\mathrm{S}} q_{\mathrm{e}}^{2}}{1+t k_{\mathrm{S}} q_{\mathrm{e}}}$

where $k_{\mathrm{S}}$ is the rate constant of pseudo-second-order adsorption ( $\mathrm{g} / \mathrm{mg} \mathrm{min})$.

The initial adsorption rate, $h(\mathrm{mg} / \mathrm{g} \min )$, is defined as:

$h=k_{\mathrm{S}} q_{\mathrm{e}}^{2}$

Nonlinear regression was followed to find the suitable model using Marquardt's percent standard deviation (MPSD) error function. The best-fit values of the model

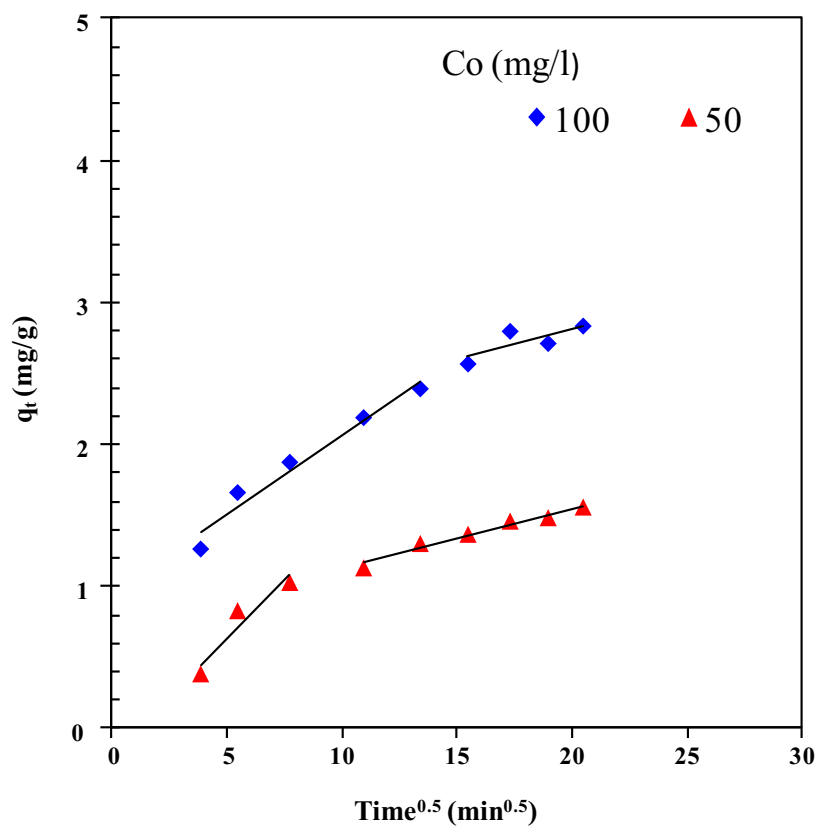

Fig. 5 CBSOL LE red wool dye adsorbed amount on CAC against square root of adsorption time $\left(q_{t}\right.$ vs. $\left.t^{0.5}\right)$

parameters, coefficient of determination $\left(R^{2}\right)$ and MPSD values are given in Table 3, and fitting is shown in Fig. 4.

As can be seen in Table 3, for pseudo-second-order model, $R^{2}$ values are higher than pseudo-first-order model fitting at both $C_{0}=50$ and $100 \mathrm{mg} / \mathrm{l}$. Also, MPSD errors are smaller for pseudo-second-order model fitting within studied concentration range of (50-100 mg/l) CBSOL red LE wool dye. Therefore, it may be concluded that pseudosecond-order kinetic model best fits the adsorption kinetics.

From Table 3 , it is observed that the $q_{\mathrm{e}}$ and $k_{\mathrm{S}}$ values were found to increase with an increase in $C_{0}$. Therefore, 
Table 4 Isotherm and thermodynamics parameters for CBSOL red LE wool dye adsorption on CAC at optimized parameters $(m=2.92 \mathrm{~g} /$ $100 \mathrm{ml}, t=6.75 \mathrm{~h}$ and $\mathrm{pH}=3.95$ )

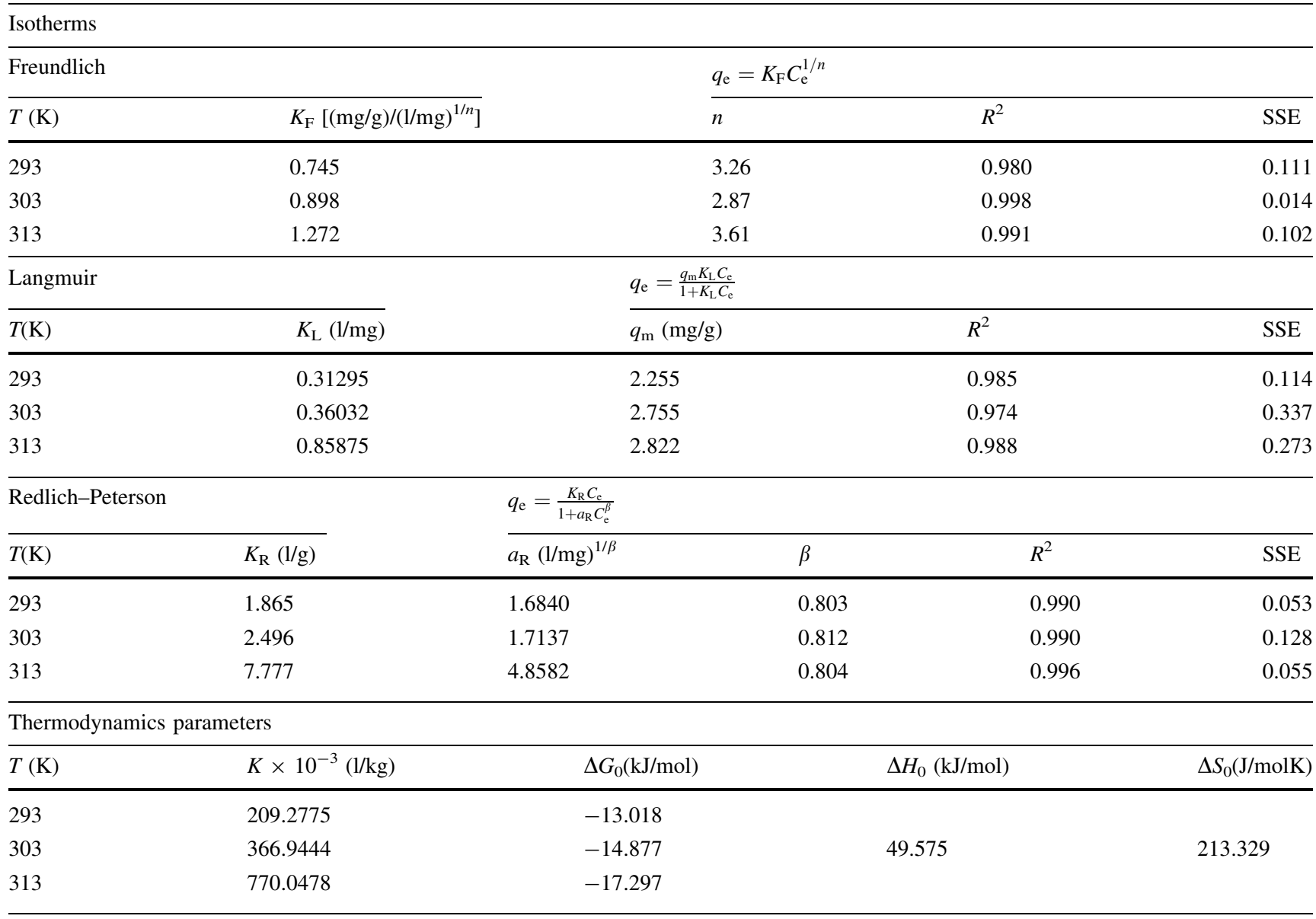

the adsorption is limited by the $C_{0}$ of CBSOL red LE wool dye.

The initial rate of adsorption $(h \mathrm{mg} / \mathrm{g} \mathrm{min})$ also increases with the increase in $C_{0}$. This also supports inference that the adsorption is limited by the $C_{0}$ of CBSOL red LE wool dye in aqueous solution.

For the calculation of diffusivity, the diffusion equation based on Fick's second law can be approximated as (Pandey et al. 2013; Ruthven 1984).

$q_{\mathrm{t}}=6 q_{\mathrm{e}}\left(\frac{D t}{\pi}\right)^{0.5}$

where $D$ is diffusivity and $q_{\mathrm{t}}$ and $q_{\mathrm{e}}$ are the adsorption capacity at any time $t$ and equilibrium, respectively.

For the calculation of diffusivity, identification of ratecontrolling step in the adsorption process is necessary. Generally, mechanism of adsorption can be explored by plotting $q_{\mathrm{t}}$ versus $t^{0.5}$ (Pandey et al. 2013; Ruthven 1984;
Kushwaha et al. 2010; Rameshraja et al. 2012) (Fig. 5). This plot shows multi-linearity due to the various steps (film or external diffusion, pore diffusion, surface diffusion and adsorption on the pore surface) involved in the adsorption process. Figure 5 shows two linear portions over time range of study, which indicate that the rate of adsorption is controlled by more than one process $(\mathrm{Ku}-$ shwaha et al. 2010; Rameshraja et al. 2012; Srivastava et al. 2006). Since, in this study, good mixing condition was provided, film or external diffusion is very fast (line not shown in Fig. 5). The second linear portion shows gradual adsorption stage where the rate is limited by intraparticle diffusion (Ramaraju et al. 2013; Srivastava et al. 2006). The third portion shows that the adsorbate concentration in the solution becomes low, and the diffusion rate is decreased (Pandey et al. 2013; Crank 1965). Therefore, in this study, pore diffusion is the rate-limiting step and slope of second linear portion provides the diffusivity. The 
Fig. 6 Equilibrium adsorption isotherms for CBSOL red LE wool dye adsorption on CAC at optimized parameters ( $m=2.92 \mathrm{~g} / 100 \mathrm{ml}, t=6.75 \mathrm{~h}$ and $\mathrm{pH}=3.95)$ a Langmuir isotherm model b Frendulich isotherm model c R-P isotherm model. Experimental data points given by symbols and the lines predicated by isotherm model

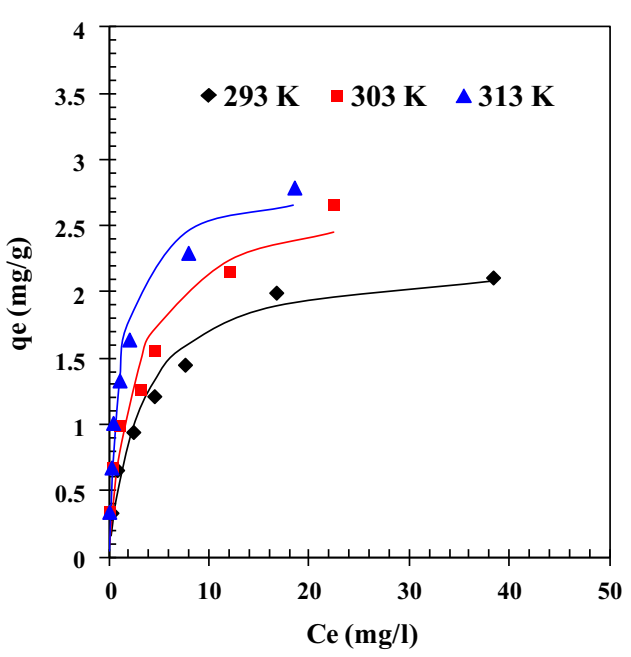

(a)

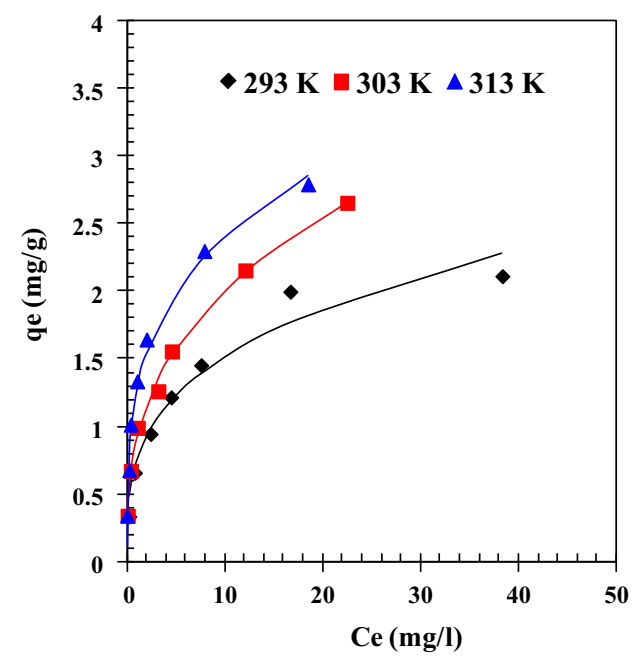

(b)

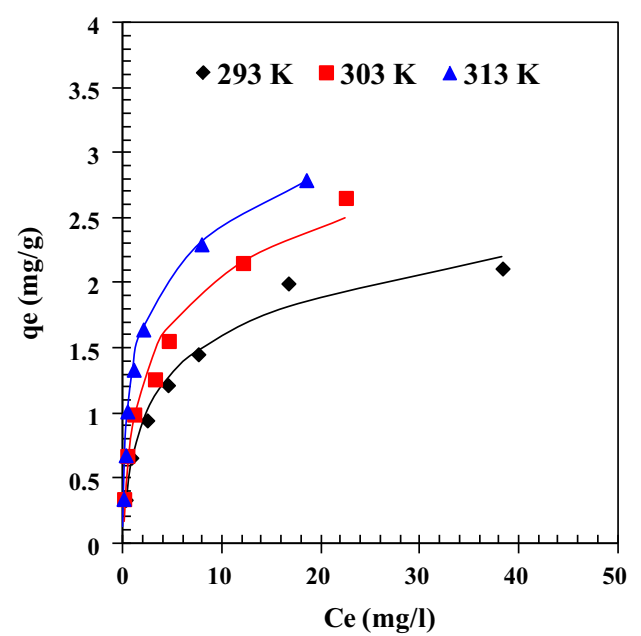

(c)

calculated diffusivity with help of Eq. 8 was found to be $9.676 \times 10^{-8}$ and $1.396 \times 10^{-8} \mathrm{~m}^{2} / \mathrm{s}$, respectively, for $C_{0}$ of 50 and $100 \mathrm{mg} / \mathrm{l}$, respectively.

Isotherm modeling and thermodynamics

Equilibrium isotherms supply the basic information for the design of adsorption systems. To study the adsorption isotherms for the CBSOL red LE wool dye adsorption onto CAC, three isotherms models Frendulich (Freundlich 1906), Langmuir (Langmuir 1918) and Redlich and Peterson (R-P) (Redlich and Peterson 1959) isotherms were analyzed.
To develop the equilibrium isotherms for CBSOL red LE wool dye adsorption onto CAC, experiments were conducted at different temperature $(T)$ ranging from 293 to $313 \mathrm{~K}$ with $C_{0}=10-100 \mathrm{mg} / \mathrm{l}$, at optimized parameters $(m=2.92 \mathrm{~g} /$ $100 \mathrm{ml}, t=6.75 \mathrm{~h}$ and $\mathrm{pH}=3.95$ ). The data obtained were then fitted to various isotherm models using nonlinear regression with sum of squares error (SSE) function. The bestfit values of the model parameters, $R^{2}$, and SSE values are given in Table 4, and fitting is shown in Fig. 6.

It was found that CBSOL red LE wool dye adsorption capacity increased with increase in $T$, concluding endothermic nature of adsorption (Fig. 6). This may be due to creation of new active surface on CAC surface at higher 
$T$ (Singh and Kushwaha 2014; Rameshraja et al. 2012). Also, the degree of diffusion within CAC structure is increased at higher $T$, enhancing the rate of intra-particle diffusion (Kushwaha et al. 2010; Aksu and Kabasakal 2004).

Table 4 shows the best-fit values of the model parameters, $R^{2}$ and SSE values. The Freundlich isotherm can be applied to heterogeneous surface. $K_{\mathrm{F}}$ and $1 / n$ are the Freundlich constants and indicate adsorption capacity and intensity, respectively (Özer et al. 2009; Kushwaha et al. 2010). Increase in $K_{\mathrm{F}}$ with increase in $T$ supports the endothermic nature of that CBSOL red LE wool dye adsorption onto CAC. The value of $n$ greater than unity concludes the favorable adsorption conditions (Özer et al. 2009). Langmuir isotherm model suggests surface homogeneity of the adsorbent (Acar and Eren 2006). $q_{\mathrm{m}}$ and $K_{\mathrm{L}}$ of Langmuir isotherm model show affinity of adsorbent to adsorbate. The value of $q_{\mathrm{m}}$ and $K_{\mathrm{L}}$ was found to increase with increase in $T$, indicating strong bonding of CBSOL red LE wool dye molecule to CAC. In R-P isotherm, there are three parameters and is applicable to both the homogenous and heterogeneous surface. Values of $\beta$ lie between 0 and 1 and signifying favorable adsorption. If $\beta=1$, the physi-sorption is the main mechanism of adsorption, and $\beta=1-(1 / n)$ shows adsorption is more heterogeneous in nature (Lakshmi et al. 2009). Table 4 shows $\beta$ values are more nearer to $[1-(1 / n)]$, indicating adsorption of CBSOL red LE wool dye on CAC is heterogeneous in nature. $R^{2}$ values for Freundlich and $\mathrm{R}-\mathrm{P}$ isotherms are higher $(\approx 0.99)$ than Langmuir isotherm, and also error function SSE values are least for the Freundlich and R-P isotherms (Table 4). Therefore, Freundlich and R-P isotherms may be used to represent the equilibrium adsorption data.

Free energy change $\left(\Delta G_{0}\right)$, enthalpy change $\left(\Delta H_{0}\right)$ and entropy change $\left(\Delta S_{0}\right)$ were also estimated with the help of equilibrium adsorption constant $(K)$ (Kushwaha et al. 2010; Acar and Eren 2006) using following equations:

$\Delta G_{0}=-R T \ln K$

$\ln K=\frac{\Delta S_{0}}{R T}-\frac{\Delta H_{0}}{R} \frac{1}{T}$

where $T$ is the absolute temperature $(K), R$ is the universal gas constant $\left(8.314 \times 10^{-3} \mathrm{~kJ} \mathrm{~mol}^{-1} \mathrm{~K}^{-1}\right)$ and $K=$ $\left(q_{\mathrm{e}} / C_{\mathrm{e}}\right)$.

Table 4 shows thermodynamic parameters at various temperatures. Positive value of $\Delta H_{0}$ and $\Delta S_{0}$ shows the endothermic nature and favorable dye adsorption, respectively (Sharma 2011; Onal et al. 2006), and the negative value of $\Delta G_{0}$ concludes spontaneous nature of adsorption
(Kushwaha et al. 2010; Srivastava et al. 2006; Lakshmi et al. 2009).

\section{Conclusion}

Optimization of adsorption process parameters for the removal of CBSOL LE red wool dye from aqueous solution by CCD under RSM was successfully applied, and quadratic model was found to best fit the experimental data. The values of $R^{2}$ and adjusted $R^{2}$ were found to be 0.894 and 0.80 , respectively.

Kinetic study showed pseudo-second-order kinetic model best fitted the data, and adsorption is limited by the CBSOL red LE wool dye concentration.

Freundlich and R-P isotherms were found to represent the equilibrium adsorption data showing $R^{2}$ value 0.99 . Increase in $K_{\mathrm{F}}$ value (Freundlich isotherm constant) with increase in $T$ concluded endothermic nature of CBSOL red LE wool dye adsorption onto CAC. In R-P isotherm, the $\beta$ values are nearer to $[1-(1 / n)]$, which indicates that the adsorption of CBSOL red LE wool dye on CAC is heterogeneous in nature. Positive value of $\Delta H_{0}$ and $\Delta S_{0}$ shows the endothermic nature and favorable dye adsorption, respectively, and the negative value of $\Delta G_{0}$ concludes spontanity of adsorption.

Acknowledgments Authors are thankful to the department of chemical engineering, Thapar University, Patiala, Punjab, India, for the financial support.

\section{References}

Acar FN, Eren Z (2006) Removal of Cu(II) ions by activated poplar sawdust (Samsun Clone) from aqueous solutions. J Hazard Mater B137:909-914

Aksu Z, Kabasakal E (2004) Batch adsorption of 2,4-dichlorophenoxy-acetic acid (2,4-D) from aqueous solution by granular activated carbon. Sep Purif Technol 35:223-240

Al-qodah Z, Shawabkah R (2009) Production and characterization of granular activated carbon from activated sludge. Braz J Chem Eng 26(1):127-136

Bansal S, Kushwaha JP, Sangal VK (2013) Electrochemical treatment of reactive black 5 textile wastewater: optimization, kinetics, and disposal study. Water Environ Res 85(12):2294-2306

Barkauskas J, Dervinyte M (2004) An investigation of the functional groups on the surface of activated carbons. J Serb Chem Soc 69(5):363-375

Behbahani M, Alavi Moghaddam MR, Arami M (2011) Technoeconomical evaluation of fluoride removal by electrocoagulation process: optimization through response surface methodology. Desalination 271:209-218 
Blanchard G, Maunaye M, Martin G (1984) Removal of heavy metals from water by means of natural zeolites. Water Res 18:1501-1507

Carrott Suhas PJM, Carrott Ribeiro MML (2007) Lignin-from natural adsorbent to activated carbon: a review. Bioresour Technol 98:2301-2312

Chakraborty S, Shamik C, Saha PD (2012) Batch removal of crystal violet from aqueous solution by $\mathrm{H}_{2} \mathrm{SO}_{4}$ modified sugarcane bagasse: equilibrium, kinetic, and thermodynamic profile. Sep Sci Technol 47:1898-1905

Chiou M, Chuang G (2006) Competitive adsorption of dye metanil yellow and RB15 in acid solutions on chemically cross-linked chitosan beads. Chemosphere 62:731-740

Chowdhury S, Saha P (2010) Sea shell powder as a new adsorbent to remove Basic Green 4 (Malachite Green) from aqueous solutions: equilibrium, kinetics and thermodynamic studies. Chem Eng J 164:168-177

Crank J (1965) The mathematics of diffusion, 1st edn. Oxford Clarendon Press, London

Freundlich HMF (1906) Over the adsorption in solution. J Phys Chem 57:385-471

Gaikwad RW, Kanawade SM, Misal SA (2010) Low cost sugarcane bagasse ash as an adsorbent for dye removal from dye effluent. Int J Chem Eng Appl 1(4):310-318

Geethakarthi A, Phanikumar BR (2011) Adsorption of reactive dyes from aqueous solutions by tannery sludge developed activated carbon: kinetic and equilibrium studies. Int $\mathrm{J}$ Environ Sci Technol 8(3):561-570

Georgiou D, Melidis P, Aivasidis A (2002) Use of a microbial sensor: inhibition effect of azo reactive dyes on activated sludge. Bioprocess Biosyst Eng 25:79-83

Gregory P (1986) Azo dyes: structure-carcinogenicity relationships. Dyes Pigm 7(1):45-56

Guven G, Perendeci A, Tanyolac A (2008) Electrochemical treatment of deproteinated whey wastewater and optimization of treatment conditions with response surface methodology. J Hazard Mater 157:69-78

Ho YS, McKay G (1999) Pseudo-second order model for adsorption processes. Process Biochem 34:451-465

Izares P, Fabiolamartianez Carlosjimeanez, Justolobato Rodrigo M (2006) Coagulation and electro coagulation of wastes polluted with dyes. Environ Sci Technol 40:6418-6424

Kushwaha JP, Srivastava VC, Mall ID (2010) Treatment of dairy wastewater by commercial activated carbon and bagasse fly ash: parametric, kinetic and equilibrium modelling, disposal studies. Bioresour Technol 101(10):3474-3483

Lakshmi UR, Srivastava VC, Mall ID, Lataye DH (2009) Rice husk ash as an effective adsorbent: evaluation of adsorptive characteristics for Indigo Carmine dye. J Environ Manag 90:710-720

Langmuir I (1918) The adsorption of gases on plane surfaces of glass, mica and platinum. J Am Chem Soc 40:1361-1403

Lemlikchi W, Khaldi S, Mecherri MO, Lounici H, Drouiche N (2012) Degradation of Disperse Red 167 Azo Dye by bipolar electrocoagulation. Sep Sci Technol 47:1682-1688

Malik PK (2003) Use of activated carbons prepared from sawdust and rice-husk for adsorption of acid dyes: a case study of Acid Yellow 36. Dyes Pigm 56:239-249

Malik R, Ramteke DS, Wate SR (2006) Physico-Chemical and surface characterization of adsorbent prepared from groundnut shell by $\mathrm{ZnCl}_{2}$ activation and its ability to absorb colour. Indian $\mathrm{J}$ Chem Technol 13:318-329
Manoochehri M, Rattan VK, Khorsand A, Panahi H (2010) Capacity of activated carbon derived from agricultural waste in the removal of reactive dyes from aqueous solutions. Carbon Lett 11(3):169-175

Montgomery DC (1996) Design and analysis of experiments, 4th edn. John Wiley \& Sons, USA

Myers RH, Montgomery DC (2002) Response surface methodology: process and product optimization using designed experiments, 2nd edn. John Wiley \& Sons, USA

Onal Y, Akmil-Basar C, Eren D, Sarıc-Ozdemir C, Depci T (2006) Adsorption kinetics of malachite green onto activated carbon prepared from tunçbilek lignite. J Hazard Mater B128:150-157

Özer A, Gürbüz G, Calimli A, Körbahti BK (2009) Biosorption of copper(II) ions on Enteromorpha prolifera: application of response surface methodology (RSM). Chem Eng J 146:377-387

Pandey NK, Velavendan P, KamachiMudali U, Natarajan R (2013) Adsorption of di-butyl phosphate on activated alumina: equilibrium and kinetics. Desalin Water Treat. doi:10.1080/19443994. 2013.839397

Parvathi C, Maruthavanan T (2010) Adsorptive removal of Megenta MB cold brand reactive dye by modified activated carbons derived from agricultural waste. Indian J Sci Technol 3(4):408-410

Rafatullaha M, Sulaimana O, Hashima R, Ahmad A (2010) Adsorption of methylene blue on low-cost adsorbents: a review. J Hazard Mater 177:70-80

Ramaraju B, Kumar Reddy PM, Subrahmanyam C (2013) Low cost adsorbents from agricultural waste for removal of dyes. Environ Prog Sustain Energy 33:38-46

Rameshraja D, Srivastava VC, Kushwaha JP, Mall ID (2012) Quinoline adsorption onto granular activated carbon and bagasse fly ash. Chem Eng J 181-182:343-351

Redlich O, Peterson DL (1959) A useful adsorption isotherm. J Phys Chem 63:1024-1026

Ruthven DM (1984) Principles of adsorption and adsorption processes. Wiley, New York

Seey TL, Noordin MJ, Kassim M (2012) Characterization of mangrove bark as a potentially low-cost adsorbent for reactive dye removal from aqueous solutions: equilibrium, mechanisms and kinetics. Int J Pure Appl Sci Technol 9(1):9-19

Sharma YC (2011) Adsorption characteristics of a low cost activated carbon for the reclamation of colored effluents containing malachite green. J Chem Eng Data 56:478-484

Singh S, Kushwaha JP (2014) Tannic acid adsorption/desorption study onto/from commercial activated carbon. Desalin Water Treat 52:3301-3311

Soo EL, Salleh AB, Basri M, Rahman RNZA, Kamaruddin K (2004) Response surface methodological study on lipase-catalyzed synthesis of amino acid surfactants. Process Biochem 39:1511-1518

Srivastava VC, Swamy MM, Mall ID, Prasad B, Mishra IM (2006) Adsorptive removal of phenol by bagasse fly ash and activated carbon: equilibrium, kinetics and thermodynamics. Colloid Surf A Physicochem Eng Asp 272:89-104

Suteu D, Malutan T, Bilba D (2011a) Agricultural waste corn cob as a sorbent for removing reactive dye orange 16: equilibrium and kinetic study. Cellulose Chem Technol 45(5-6):413-420

Suteu D, Zaharia C, Malutan T (2011b) Removal of Orange 16 reactive dye from aqueous solutions by waste sunflower seed shells. J Serb Chem Soc 76(4):607-624 
Weng CH, Lin YT, Tzeng TW (2009) Removal of methylene blue from aqueous solution by adsorption onto pineapple leaf powder. J Hazard Mater 170:417-424
Yazdani M, Mahmoodi NM, Arami M, Bahrami H (2012) Isotherm, kinetic, and thermodynamic of cationic dye removal from binary system by Feldspar. Sep Sci Technol 47(2-12):1660-1672 